\title{
The Quest for Luschka's Duct: An Eponym Leading a Life of Its Own?
}

\author{
Elizabeth A. Boonstra Karlotta Lorenz Robert J. Porte \\ Division of Hepatobiliary Surgery and Liver Transplantation, Department of Surgery, University Medical Center \\ Groningen, University of Groningen, Groningen, The Netherlands
}

\section{Key Words}

Duct of Luschka $\cdot$ Eponym · Biliary anatomy

\begin{abstract}
Background: The German anatomist Hubert von Luschka gave name to several structures in the human body. One of great discussion is the duct of Luschka, part of the biliary system. There are different descriptions of the duct of Luschka. This might lead to confusion in the debate and as to what therapy should best be provided in case of an injured duct of Luschka. Methods: We reviewed the literature on descriptions of Luschka's duct and studied the original German descriptions by Hubert von Luschka. Results: While reading the original work by von Luschka on the hepatobiliary system, we were not able to find a description of either one of the two structures that are nowadays referred to as 'the duct of Luschka'. Conclusions: von Luschka maybe never described the so-called duct of Luschka. He did, however, describe the peribiliary glands in the intra- and extrahepatic bile ducts and gallbladder wall. These might have been misinterpreted as a duct running along the gallbladder fossa. The lack of a clear definition is the reason for the development of rather confusing and sometimes misleading eponyms as the duct of Luschka. The eponym 'duct of Luschka' should, therefore, better not be used.

(c) 2014 S. Karger AG, Basel
\end{abstract}

\section{Introduction}

When a patient after a laparoscopic or open cholecystectomy is suffering biliary leakage, the possibility of leakage from a 'duct of Luschka' is generally included in the differential diagnosis. We noticed two different descriptions of the duct of Luschka in the surgical and anatomical literature. This has led to a confusing debate in our surgical team as to what therapy should best be provided in case of an assumed biliary leakage from an injured duct of Luschka during a cholecystectomy. To setthe this debate we decided to review the literature on descriptions of Luschka's duct and, most importantly, we studied the original German descriptions by Hubert von Luschka.

\section{Who Was Hubert von Luschka?}

Hubert von Luschka was born on July 27,1820 , in Konstanz, Germany. He began studying medicine in 1841 at the University of Heidelberg and the University of Freiburg. After completing his studies in 1844, he started working at the University of Tubingen at the prestigious department of anatomy where he became a professor in anatomy and pathology in 1852. In 1855, he

\section{KARGER}

E-Mail karger@karger.com

www.karger.com/dsu
(C) 2014 S. Karger AG, Basel

0253-4886/14/0312-0104\$39.50/0
Elizabeth A. Boonstra, MD

University Medical Center Groningen PO Box

NL-9700 RB Groningen (The Netherlands)

E-Mail e.a.boonstra@ chir.umcg.nl 
took over the position of the director of the anatomical institute (fig. 1).

von Luschka's specific interest was human anatomy and its relation with surgery. In general he focused on descriptive, topographic and comparative anatomy and developed new techniques how to prepare the specimen. He used seemingly normal corpses without underlying pathology for his research. This made it possible to study structures in non-diseased humans. His devotion led to important new knowledge about the human body and offered new research possibilities.

von Luschka summarized all of his findings in meticulous books, one of the most important being the very detailed 'Anatomie des Menschen in Rücksicht auf das Bedürfnis der praktischen Heilkunde' (Human Anatomy in Consideration of the Needs of Practical Medicine) [1]. In this German book, he described the entire human anatomy in words, taking into account all its possible variations. Several wood-cut illustrations are added in order to illustrate his writings and to clarify the location and function of organs and structures.

\section{Eponyms in Medicine}

Eponyms are part of the nomenclature in medicine. Eponyms usually refer to a person who discovered or first described an anatomical structure, symptom, disease, therapy, or a medical instrument. The person may have given his/her name to this entity him/herself or others have connected the name to it. Eponyms are ubiquitous in medicine but there is discussion about the use of eponyms in medical communication. Opponents claim that they lack accuracy, lead to confusion and hamper scientific discussion [2]. Others think eponyms embellish medicine $[3,4]$.

\section{What Is Considered as the Duct of Luschka in Modern Literature?}

There are several eponyms referring to Hubert von Luschka. One of these is the 'duct of Luschka', which is considered a part of the biliary system. When reviewing the literature, this eponym, however, seems to be used for different structures.

Most authors describe the duct of Luschka as one or more small bile duct(s) located in the gallbladder fossa that branch(es) from the right hepatic of common hepatic duct and have a blind proximal end, not draining any liver parenchyma. Most papers refer to the original writings of Hubert von Luschka in which these ductules were supposedly described [4-8]. Others have suggested that the duct of Luschka is a small bile duct running along the gallbladder fossa, draining bile from the liver parenchyma directly into the gallbladder (usually part of segment 5) [9].

It is important to have a clear definition of an eponym as the duct of Luschka. Injuries to the so-called 'duct of Luschka' typically occur during (laparoscopic) cholecystectomy and result in intraperitoneal bile leakage and formation of biloma. The two different structures nowadays called duct of Luschka imply different treatment strategies when injured. A blind ending duct connecting to the right or common hepatic duct can be decompressed by endoscopic retrograde cholangiopancreatography and stent placement (either with or without sphincterotomy) [10], whereas an injury to a bile duct draining an isolated part of liver parenchyma cannot be treated this way. Using a clear and uniform definition of the duct of Luschka in medical communication is therefore important.

\section{Tracking Down the Original Description of Luschka's Duct}

It is unclear which anatomic bile duct variation was originally described by von Luschka. Standard works on hepatobiliary surgery and articles describing the duct of Luschka all refer to his textbook of clinical anatomy, of which the second volume is dedicated to the abdomen [1]. We were able to find an original copy of von Luschka's textbook in our university library. While reading this original work by von Luschka on the hepatobiliary system, we were not able to find a description of either one of the two structures that are nowadays referred to as 'the duct of Luschka'. We found no descriptions of ducts or small ductules running through the gallbladder fossa, connecting with the right or common hepatic duct or draining an isolated section of liver parenchyma directly into the gallbladder.

Hubert von Luschka, however, did describe dimples in the wall of bile ducts, which he considers to be a sort of gland. von Luschka called these anatomical structures 'drüssen', which can be translated as 'grapes' (fig. 2). Most of these glands described by von Luschka were found in the intrahepatic bile ducts and in the common bile duct. To a much smaller extent these dimples were seen in the gallbladder wall. He did not consider his discoveries of great significance. In the absence of any other description 
1

Fig. 1. Portrait of Hubert von Luschka. Source: http://www.zeno.org - Zenodot Verlagsgesellschaft $\mathrm{mbH}$ (copyright-free). Fig. 2. Glands from the gallbladder wall as illustrated by von Luschka in his textbook [1].
2

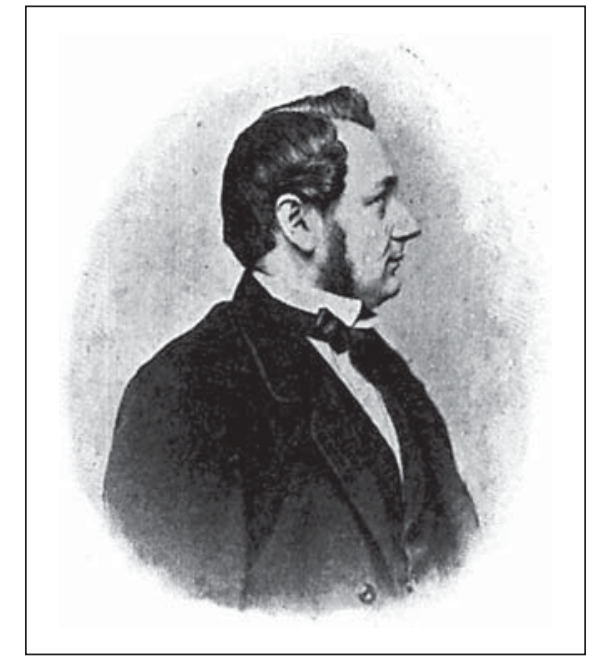

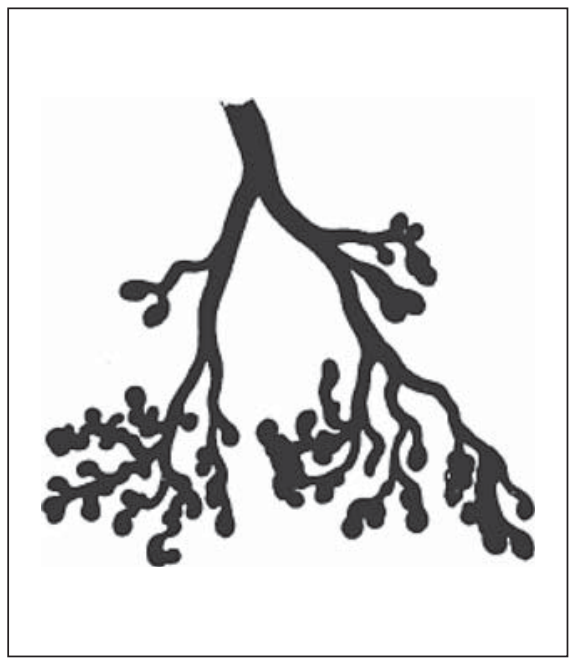
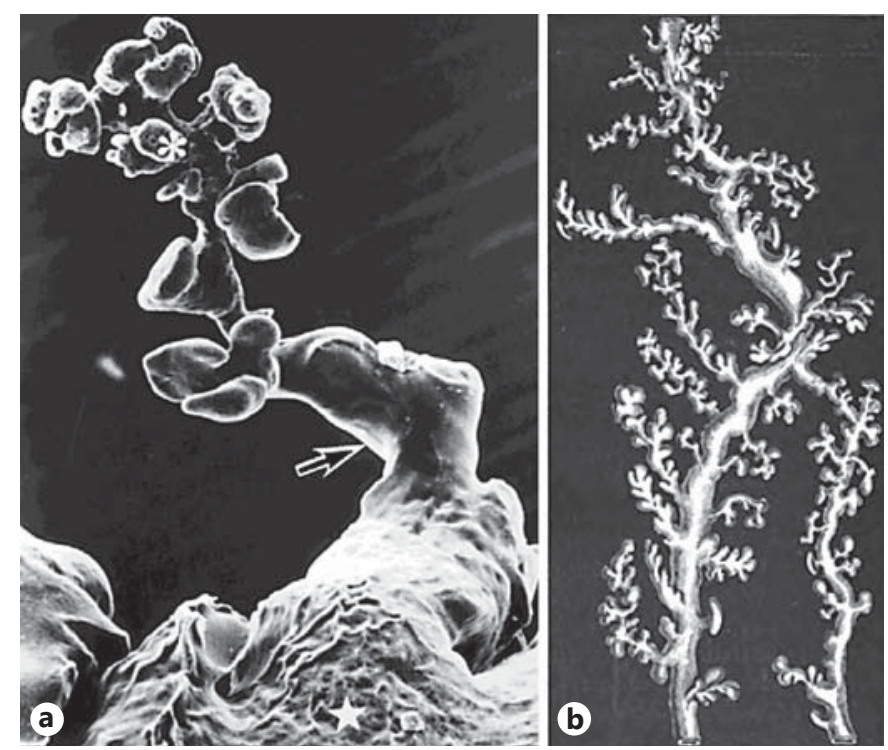

Fig. 3. a Scanning electron microscopy of the peribiliary glands. Reproduced with permission from Ishida et al. [11]. b Grape-like glandular appendices ('drüssen') of the bile ducts as illustrated by von Luschka [1].

by von Luschka that matches today's meaning of the eponym, we believe that 'the duct of Luschka' is a misinterpretation of these glandular structures described by him in the gallbladder wall.

The glands that von Luschka described are now known as the peribiliary glands. A detailed description of these peribiliary glands was given by Ishida et al. [11] in 1989 . The electron microscopy pictures in this publication are of striking similarity with the wood-cut illustrations in von Luschka's anatomy book (fig. 3). More recent research has suggested that the peribiliary glands are a local niche of progenitor cells, which play an important role in the recovery process and renewal of the bile duct epithelium after injury $[12,13]$.

\section{Conclusion}

The course of time as well as the fact that von Luschka described different parts of the human body made his name accountable for many structures. It seems that the reason why several approaches concerning this anatomical structure are present is the fact that von Luschka maybe never described this duct. He did, however, describe the peribiliary glands in the intra- and extrahepatic bile ducts and gallbladder wall, which might have been misinterpreted as a duct running along the gallbladder fossa. The lack of a clear definition is reason for the development of rather confusing and sometimes misleading eponyms as the duct of Luschka. Eponyms are a complicating factor in anatomy and may be deceptive. With regard to the duct of Luschka the use of this eponym in medical communication is confusing and hampers scientific discussion since different structures are meant. The eponym 'duct of Luschka' should, therefore, better not be used.

\section{Disclosure Statement}

No funding has been received for this study. 


\section{References}

$>1$ Ahrendt SA, Pitt HA: Surgical therapy of iatrogenic lesions of biliary tract. World J Surg 2001;25:1360-1365.

2 Chiruvella A, Sarmiento JM, Sweeney JF, Lin E, Davis SS Jr: Iatrogenic combined bile duct and right hepatic artery injury during single incision laparoscopic cholecystectomy. JSLS 2010;14:268-271.

-3 Sarmiento JM, Farnell MB, Nagorney DM, Hodge DO, Harrington JR: Quality-of-life assessment of surgical reconstruction after laparoscopic cholecystectomy-induced bile duct injuries: what happens at 5 years and beyond? Arch Surg 2004;139:483-488; discussion 488-489.

4 Jablonska B: Hepatectomy for bile duct injuries: when is it necessary? World J Gastroenterol 2013;19:6348-6352.

$>5$ Bektas H, Schrem H, Winny M, Klempnauer J: Surgical treatment and outcome of iatrogenic bile duct lesions after cholecystectomy and the impact of different clinical classification systems. Br J Surg 2007;94:1119-1127.
6 Boerma D, Rauws EA, Keulemans YC, Bergman JJ, Obertop H, Huibregtse K, et al: Impaired quality of life 5 years after bile duct injury during laparoscopic cholecystectomy: a prospective analysis. Ann Surg 2001;234:750 757.

7 Fischer CP, Fahy BN, Aloia TA, Bass BL, Gaber AO, Ghobrial RM: Timing of referral impacts surgical outcomes in patients undergoing repair of bile duct injuries. $\mathrm{HPB}(\mathrm{Ox}-$ ford) 2009; 11:32-37.

8 Sarmiento JM, Farnell MB, Nagorney DM, Hodge DO, Harrington JR: Quality-of-life assessment of surgical reconstruction after laparoscopic cholecystectomy-induced bile duct injuries: what happens at 5 years and beyond? Arch Surg 2004;139:483-488; discussion 488-489.
9 Lau WY, Lai EC, Lau SH: Management of bile duct injury after laparoscopic cholecystectomy: a review. ANZ J Surg 2010;80:75-81.

10 Stewart L, Way LW: Laparoscopic bile duct injuries: timing of surgical repair does not influence success rate. A multivariate analysis of factors influencing surgical outcomes. HPB (Oxford) 2009;11:516-522.

11 Ishida F, Terada T, Nakanuma Y: Histologic and scanning electron microscopic observations of intrahepatic peribiliary glands in normal human livers. Lab Invest 1989;60:260265.

12 Sutton ME, op den Dries S, Koster MH, Lisman T, Gouw AS, Porte RJ: Regeneration of human extrahepatic biliary epithelium: the peribiliary glands as progenitor cell compartment. Liver Int 2012;32:554-559.

13 Lim JH, Zen Y, Jang KT, Kim YK, Nakanuma Y: Cyst-forming intraductal papillary neoplasm of the bile ducts: description of imaging and pathologic aspects. Am J Roentgenol 2011;197:1111-1120. 